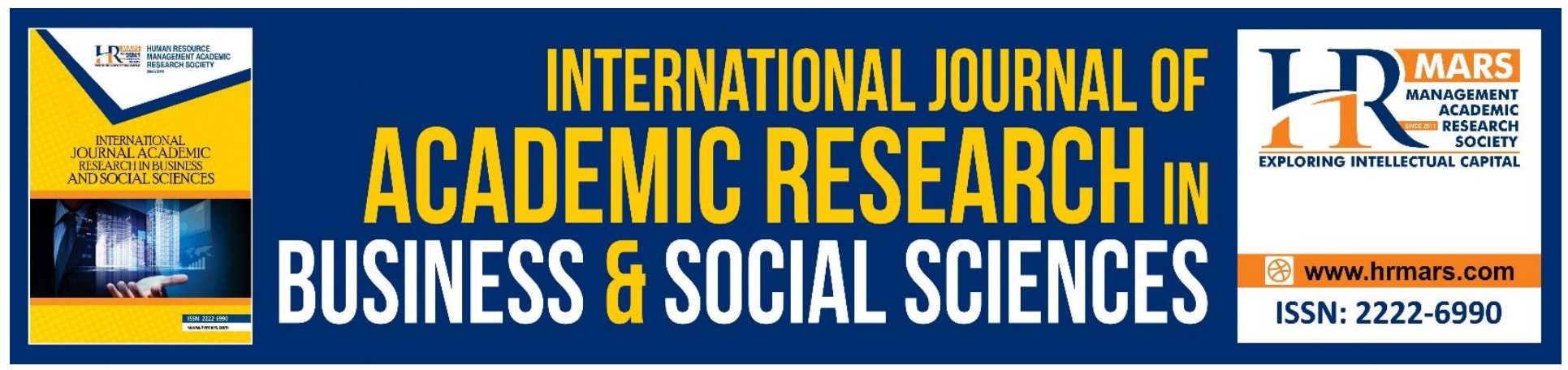

\title{
Counseling Needs of the Students in Psychological and Educational Counseling Program at Hebron University from the Students' Perspective
}

Najihah Abd Wahid, Hasan Hih, Anas Mohd Yunus

To Link this Article: http://dx.doi.org/10.6007/IJARBSS/v8-i10/4734

DOI: 10.6007/IJARBSS/v8-i10/4734

Received: 21 Sept 2018, Revised: 17 Oct 2018, Accepted: 19 Oct 2018

Published Online: 31 October 2018

In-Text Citation: (Wahid, Hih, \& Yunus, 2018)

To Cite this Article: Wahid, N. A., Hih, H., \& Yunus, A. M. (2018). Counseling Needs of the Students in Psychological and Educational Counseling Program at Hebron University from the Students' Perspective. International Journal of Academic Research in Business and Social Sciences, 8(10), 287-299.

Copyright: (C) 2018 The Author(s)

Published by Human Resource Management Academic Research Society (www.hrmars.com) This article is published under the Creative Commons Attribution (CC BY 4.0) license. Anyone may reproduce, distribute, translate and create derivative works of this article (for both commercial and non-commercial purposes), subject to full attribution to the original publication and authors. The full terms of this license may be seen at: http://creativecommons.org/licences/by/4.0/legalcode

Vol. 8, No. 10, 2018, Pg. 287 - 299

Full Terms \& Conditions of access and use can be found at http://hrmars.com/index.php/pages/detail/publication-ethics 


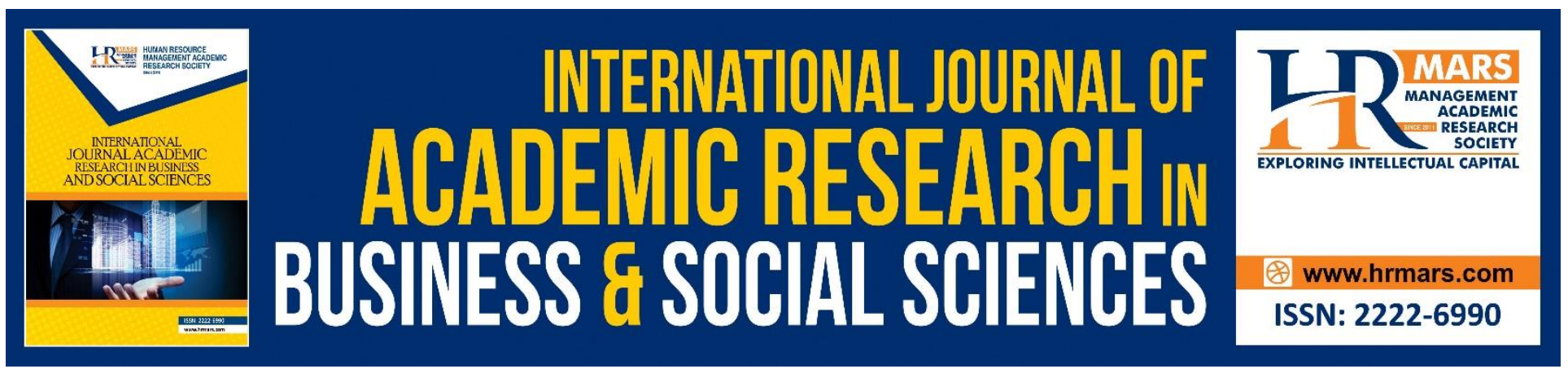

\title{
Counseling Needs of the Students in Psychological and Educational Counseling Program at Hebron University from the Students' Perspective
}

\author{
Najihah Abd Wahid \\ Research Institute for Islamic Products \& Civilization (INSPIRE), UniSZA, Malaysia
}

\section{Hasan Hih}

Hasan M. SH Hih, Department of Psychological and Educational Counseling at Al-Istiqlal University, Palestine

\author{
Anas Mohd Yunus \\ Faculty of Islamic Contemporary Studies, UniSZA, K.Trg, Malaysia \\ Email:anas@unisza.edu.my
}

\begin{abstract}
This study aims to identify the counseling needs of the students in Psychological and Educational Counseling program at Hebron University from the students' own point of view, particularly the nature and importance of these needs among the students due to their great influence in building the students' personality. In order to achieve the objectives of this study, questionnaire was developed and administered to a selected sample of 98 male and female students. A number of findings were obtained in this study, the most important of which are: There is a number of psychological and educational counseling needs of Hebron University students. The most important of these needs is to identify the students' needs and problems. Several recommendations are offered in this study, the most important of which is: Particular attention should be paid to the needs of counseling program students by offering various guidance models and applying them in reality.
\end{abstract}

Keywords: Counseling Needs, Psychological Counseling, Hebron University

\section{Introduction}

Psychological and educational counseling needs are considered necessary for students at all stages, particularly their university lives. This is because they play an important role in refining the people's personality at each stage of their life, especially as each stage has different purposes and considerations. Taking into consideration the fulfillment of all these requirements and factors which 
contribute significantly to the students' progress in the educational, psychological and social aspects at each of these stages, the importance of guidance and counseling and how to satisfy its requirements have been highlighted. Psychological and Educational guidance contributes to the fulfillment of the students' needs and desires, which could help them to succeed in the future stages in their life, especially as there are many influential factors throughout these stages. At times, these factors can be astonishing and surprising as a result of changes faced by the individual, both at the psychological and educational levels. Therefore, it is necessary to raise awareness of the need to work on the development of these changes and the skills of managing and overcoming them by providing various methods of educational counseling aimed at helping the individual toward progress.

The university level, which is one the most important stages in students' life, specifically integrates the students in a new multicultural society and doctrines. This highlights the importance of psychological, educational and social guidance, which guides the students to familiarize themselves with the community. This is highly significant because the university serves as one of the advanced stages in the students' life as it prepares them to become relevant to the society. In addition, this stage contributes significantly to societal development and prosperity. Consequently, the university is of great importance in the development of people's personality, which in turn contributes significantly to the development of the society in general (Aitah \& al-Tahan, 2002).

Students face many challenges at the university, which indicates the need to provide guidance and counseling programs at various levels, especially to meet all his educational, psychological, social and educational needs and help the students to choose programs that are consistent with their situations, abilities and interest. This is because at times individuals do not have the ability to identify their needs due to lack of knowledge and experience in this direction, which requires the effort of competent authorities at the universities to provide awareness programs through seminars and lectures. This can contribute significantly to guiding the students toward their desired objectives and understanding consistent with their abilities, situation, and interest.

The centers of psychological and educational guidance at universities are very important and must be given more attention. Their development could serve the society, especially as university students are among the most important group due to the changes, pressures, and challenges they face in their daily lives. This issue requires efforts and initiatives in order to identify the students' needs and provide them with the necessary assistance by providing qualified and trained personnel who would provide the students with counseling, educational, psychological and social services. Providing these services will contribute significantly in refining the individual's personality and progress at this stage, which is the most important stage in their lives. It is particularly imperative to guide individuals in confronting the difficulties they face, consult these centers and request assistance in order to overcome and confront the difficulties, which would be of great importance in refining and building the individual's personality to be able to progress and succeed at the personal, social, and practical levels.

\section{Background of the Study}

Psychological, educational and social counseling needs are among the most important needs of university level students, especially as they play a major role in refining and building the students' 
personality at the psychological, social, educational, behavioral and scientific levels. In addition, they contribute significantly to the societal development and prosperity by building individuals capable of bringing about change, progress and development at the personal and societal level. Specifically, university is one of the most important stages in this direction.

The problem in the present study was to identify the importance of counseling needs of the students in psychological and educational counseling program at Hebron University from the students' own perspective, base on which the following main question is raised:

What is the importance of counseling needs of the students in psychological and educational counseling program at Hebron University from the students' perspective?

\section{Methodology of this Study}

This study employed analytical descriptive approach due to its suitability in studying the facts about a particular phenomenon. It is recognized as an accurate description, and it uses both qualitative and quantitative analysis. This approach is used to collect and analyze facts and information about a particular phenomenon in order to provide valid conclusion and recommendations. The data were obtained from both primary and secondary sources. The analytical descriptive approach is based on interpreting the phenomenon under study by identifying the relevant issues and describing their relationship in order to arrive at an accurate scientific conclusion regarding the problem. This approach goes beyond the process of describing the phenomenon. It also includes analysis, measurement, and interpretation of the data to obtain accurate description of the phenomenon and its outcomes.

\section{Population of the Study}

The population of this study comprises the students of psychological and educational guidance at Hebron University, amounting to 120 male and female students according to the statistics of Palestinian Ministry of Education and Higher Education for 2017/2018 academic year. The university is situated in Hebron governorate in the West Bank.

\section{Population Sample}

The researchers relied on comprehensive survey method for the unit of sampling, which comprises the students of psychological and educational counseling at Hebron University, amounting to 120 students. This is based on the statistics of Palestinian Ministry of Education and Higher Education for 201712018 academic year. A sample of 120 students was randomly selected from psychological and educational counseling program. The questionnaire was administered to the population sample, from which $98 \%$ of the total administered questionnaire was retrieved and considered valid for statistical analysis.

\section{Research Instrument}

To achieve the objectives of this study, a questionnaire was developed based on previous studies and consultation of experts in the area of psychological and educational counseling from academic and professional fields. The questionnaire was divided into two parts: the personal data of the 
INTERNATIONAL JOURNAL OF ACADEMIC RESEARCH IN BUSINESS AND SOCIAL SCIENCES

Vol. 8, No. 10, Oct. 2018, E-ISSN: 2222-6990 ㄷ 2018 HRMARS

respondents and questions related to the study area. Five-point Likert scale was used to determine the significance of each item in the questionnaire in order to measure the responses for each contract.

\section{Validation of the Questionnaire}

The questionnaire was given to a group of raters consisting of 5 experts in the field of psychological counseling and statistics to provide their opinions on the suitability of the questionnaire items, and to validate the language accuracy and clarity. The questions were modified based on the responses provided by the raters.

\section{Consistency of the Research Instrument}

The internal consistency of the research instrument was determined using the Cronbach's alpha coefficient for each item in the questionnaire. The consistency coefficient was high, which indicates strong consistency of the questionnaire. Consistency value is shown in Table 1 below.

Table 1: The value of Cronbach's alpha coefficient internal consistency of each Construct

Construct Items Cronbach's alpha

Psychological and educational counseling needs of students in psychological and educational counseling program at Hebron University $\quad 1-8 \quad 0.71$

Difficulties and obstacles facing the psychological and educational needs of students in psychological and educational counseling program at Hebron University 9-17 $\quad 0.76$

The suggestions that can be obtained through psychological and educational needs of the students in psychological counseling and educational program at the Hebron University $\quad \begin{array}{lll}18-24 & 0.81\end{array}$

The information in Table 1 shows that the consistency coefficient of the research instrument ranged between $0.71-0.81$. Such values are acceptable in the present study.

\section{Previous Studies Related to the Importance Of Counseling Program}

A study conducted by Ibn Zaid (2010) aimed to measure the effectiveness of a counseling program for the development of rational thinking from a sample of students at Ain Shams University and its effect on the variables of anger and satisfaction with life. The study used a measure of irrational ideas, one for anger and one for satisfaction with life. It was designed according to Albert Ellis's behavioral rationality theory, which was applied to the experimental group. After the statistical analysis of the data, the results showed the program's effectiveness in the development of rational thinking, and in reducing the level of anger, as well as increasing the degree satisfaction with life among participants in the experimental group, when comparing their scores and degree of measurement with those of the control group.

Al-Maghamsi's (2007) study aimed to identify the role of educational guidance at universities in meeting the development national manpower requirements. The study also highlighted the importance of educational guidance in achieving quality education for students in all aspects of their personalities and preventing them from destructive cultures and ideas, as well as guiding them to join disciplines according to their wishes and abilities based on the manpower development needs. 
This helps the students to make great achievement in their studies at the university level and choose suitable professions after graduation.

The study identified the most important counseling services for students in universities, which could contribute to meeting the development needs of qualified national manpower. This consists of the early guidance from the university's counseling officers for secondary school students applying for admission into universities to choose suitable specialties based on their wishes and abilities. It aims to help students adapt to and succeed in their studies, by taking care of the students in all aspects of their personalities and giving attention to outstanding students and those who are left behind, as well as helping the students to identify their interests and abilities. Early guidance is intended to guide students to the most appropriate ways of learning and enhancing academic achievement.

In addition, the study identified the most important achievements of effective educational guidance at universities in terms of their contribution in meeting the manpower development needs by determining the balance between the outputs of higher education and the development manpower needs, as well as comprehensive education for students in all aspects of their personalities. Effective educational guidance improves the internal and external productivity of the University, reduces educational and economic loss, and increases the effectiveness and motivation of students' learning to achieve the basic objective of development.

Shaheen (2009) conducted a study to identify the problems of students at Al-Quds Open University, and the difference between these problems according to the variables of sex and age groups. The study aimed to evaluate the students' guidance needs in order to plan for the provision of counseling services at the university to help them address their educational, social and psychological issues. To this end, a questionnaire was developed, consisting of 46 items distributed to a random sample 613 students. The findings showed that the major problems faced by students at Al-Quds Open University include unfavorable examination condition, unfavorable atmosphere for study, and the failure of academic supervisors to facilitate effective curriculum development and the need for increased students' motivation.

Nuri and Yahya (2007) identified the students' educational and psychological needs at University of Mosul and determined the differences in the consoling needs according to the variables of sex and level. The study population amounted to 422 male and female students. The researchers developed a questionnaire to specifically measure the needs of 50 students. The questionnaire consisted of 35 items, which were statistically measured using Fisher equation and Chi-square test. The study discovered 9 critical needs, 6 of which are educational needs, 2 psychological needs, and 1 social need.

A study conducted by Bardini (2006) aimed to identify the reality of educational guidance in the public schools in Gaza governorates and determine the major problems facing educational counselors and appropriate solutions to the problems. The researcher developed a questionnaire as research instrument consisting of 45 items. The study investigated problems related to preparation and 
INTERNATIONAL JOURNAL OF ACADEMIC RESEARCH IN BUSINESS AND SOCIAL SCIENCES

Vol. 8, No. 10, Oct. 2018, E-ISSN: 2222-6990 ㄷ 2018 HRMARS

training, administration, teaching environment, and working conditions of the counselors. Descriptive analytical method was used to analyze the data. The most important findings of the study indicated that there is agreement and difference in the major problems facing educational and psychological counselors.

\section{A Review of the Previous Studies and their Relevance to the Present Study}

The previous studies confirmed the need to study counseling needs and identify their importance among university students. This is because they are of great importance in providing the students with skills to manage the situations and difficulties they might face in their daily lives. Some studies have also shown the students' uncertainty about their counseling needs in terms of concept and priority. The studies recommended the need to direct and guide the students according to their wishes, desires, and directions, which meets their psychological, educational, and social needs. The relationship between this study and the previous studies lies in the need to study psychological counseling as one of the most important concepts and fundamentals in universities and determine its role in providing solutions to what the studies confirmed of many difficulties facing the students on a continuous basis. These obstacles prevent the students' psychological adaptation with themselves and the environment, which obstructs their progress and creativity in various scientific, social and professional as aspects of their lives. The relationship is also evident in the fact that this study was based on the weaknesses of some previous studies in identifying the students' understanding through their personal level of knowledge. It is obtained from the students' understanding of their psychological, educational, and social needs, which indicates the need to focus on such area of study that aims to effectively enhance the students' personality.

\section{Findings}

The findings of this study is presented and interpreted according to the sequence of the research questions and hypotheses. The five-likert scale used in the study is taken into consideration as follows.

Strongly agree Agree Neutral Disagree Strongly disagree

(2)

Based on the above scale, the mean value obtained in this study is used to interpret the data as follows.

High Moderate Low

3.66 and above 2.33-3.65 2.32 and below

Therefore, if the mean value of the item is greater than or equal to 3.66 , the level of perception is high. This means that the respondents agree with the statement. Also, if the mean value of the item is between 2.33 and 3.65, the level of perception is average. Meanwhile, a mean value of 2.32 and below indicates that the level of perception is low. The following is a detailed presentation and discussion of findings. 
INTERNATIONAL JOURNAL OF ACADEMIC RESEARCH IN BUSINESS AND SOCIAL SCIENCES

Vol. 8, No. 10, Oct. 2018, E-ISSN: 2222-6990 @ 2018 HRMARS

The first research question asks: What are the counseling, educational, and social needs of the students in psychological and educational counseling program at Hebron University from the students' perspective? In order to address this question, the mean value and standard deviation were calculated based on the respondents' perception for each item related to the counseling and educational needs of the students in psychological and educational counseling program at Hebron University.

Table 2

Mean value and standard deviations of the respondents' perception about counseling and educational needs of the students in psychological and educational counseling program at Hebron University

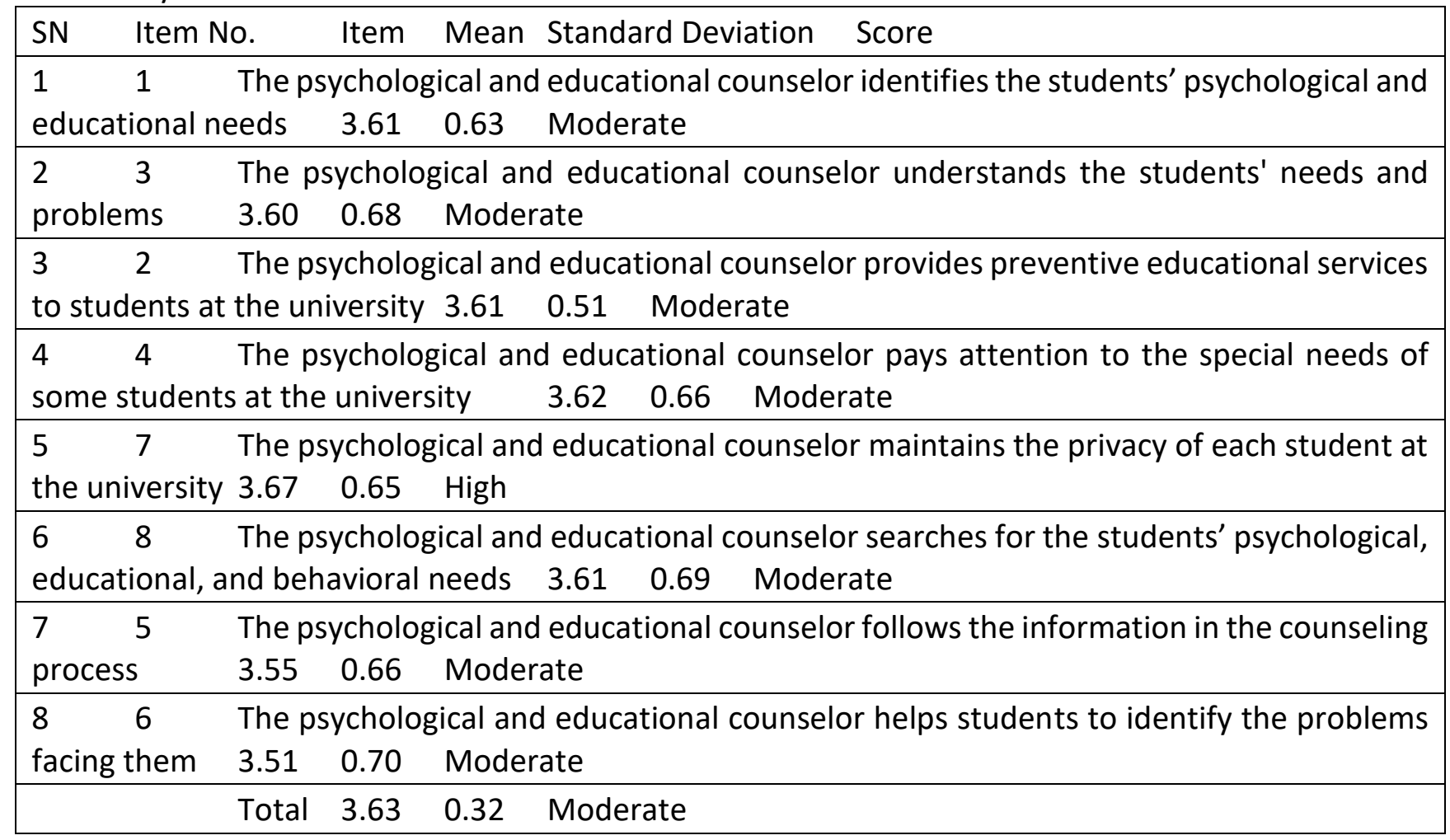

Table 2 shows that the respondents' perception about the counseling and educational needs of the students in psychological and educational counseling program at Hebron University is moderate with a mean value of 3.63 and a standard deviation of 0.32 . Item 7 "The psychological and educational counselor maintains the privacy of each student at the university" ranked first with a high mean score of 3.67. Item 6 "The psychological and educational counselor helps students to identify the problems facing them" ranked last with a moderate mean score of 3.51 .

The second research question asks: What are the difficulties and obstacle facing the students in psychological and educational counseling program at Hebron University from the students' perspective? In order to address this question, the mean and standard deviations about the respondents' perception about each statement were calculated. 
INTERNATIONAL JOURNAL OF ACADEMIC RESEARCH IN BUSINESS AND SOCIAL SCIENCES

Vol. 8, No. 10, Oct. 2018, E-ISSN: 2222-6990 @ 2018 HRMARS

Table 3

Mean value and standard deviations of the respondents' perception about the difficulties and obstacles facing the students in psychological and educational counseling program at Hebron University

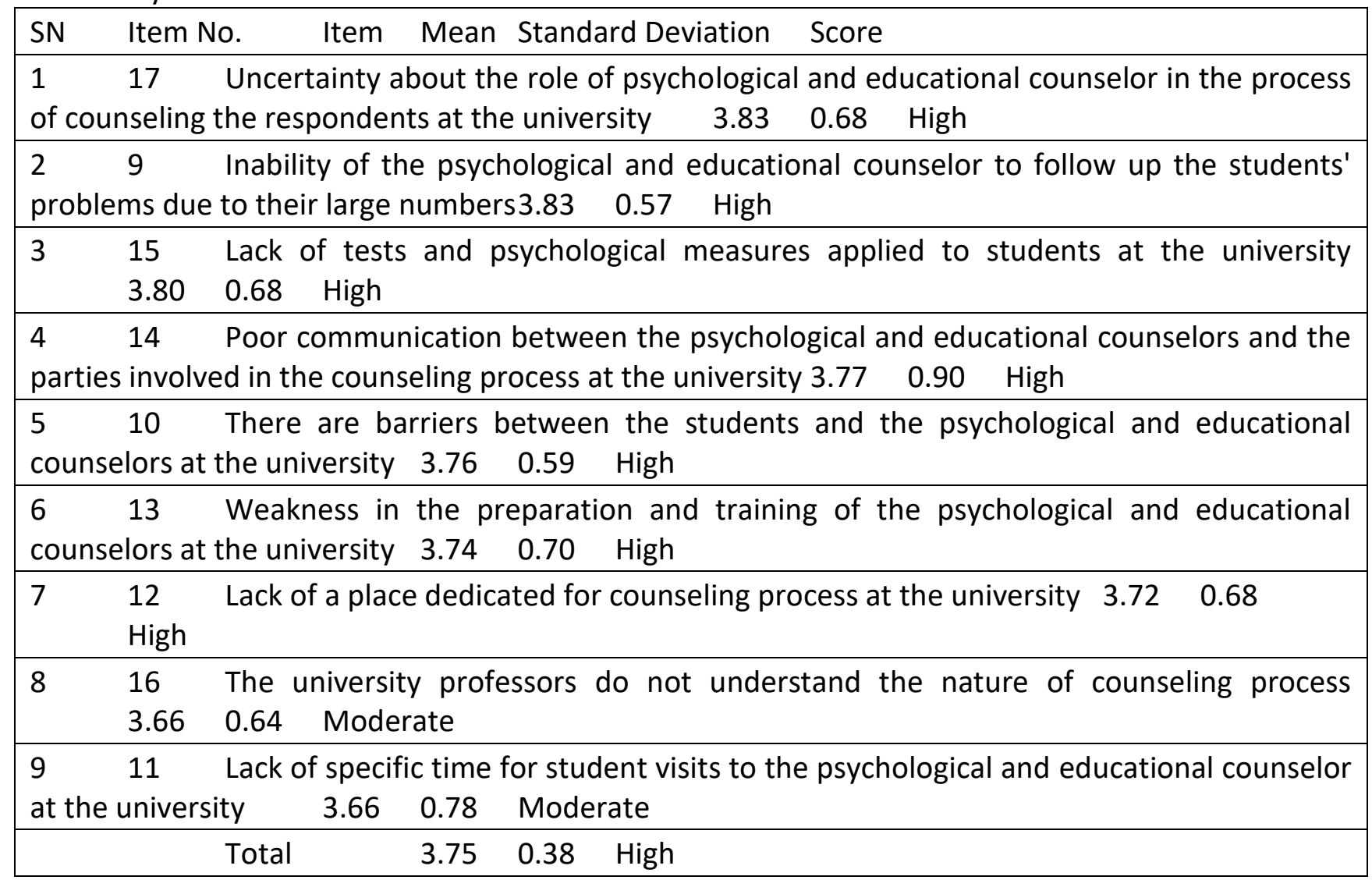

Table 3 shows that the respondents' perception about the difficulties and obstacles facing the students in psychological and educational counseling program at Hebron University is high, with mean score of 3.75 and a standard deviation of 0.38 . Item 17: "Uncertainty about the role of psychological and educational counselor in the process of counseling the respondents at the university" ranked first with a high mean score of 3.87. Item 11: "Lack of specific time for student visits to the psychological and educational counselors at the university" ranked last with a moderate mean score of 3.66 .

The third research question asks: What are the proposals through which the counseling, educational and psychological needs of the students in psychological and educational counseling program at Hebron University can be achieved? In order to address this question, the mean and standard deviations for the respondents' perception about each statement were calculated. 
INTERNATIONAL JOURNAL OF ACADEMIC RESEARCH IN BUSINESS AND SOCIAL SCIENCES

Vol. 8, No. 10, Oct. 2018, E-ISSN: 2222-6990 ㄷ 2018 HRMARS

Table 4

Mean value and standard deviations of the respondents' perception about the proposals through which the counseling, educational and psychological needs of the students in psychological and educational counseling program at Hebron University can be achieved

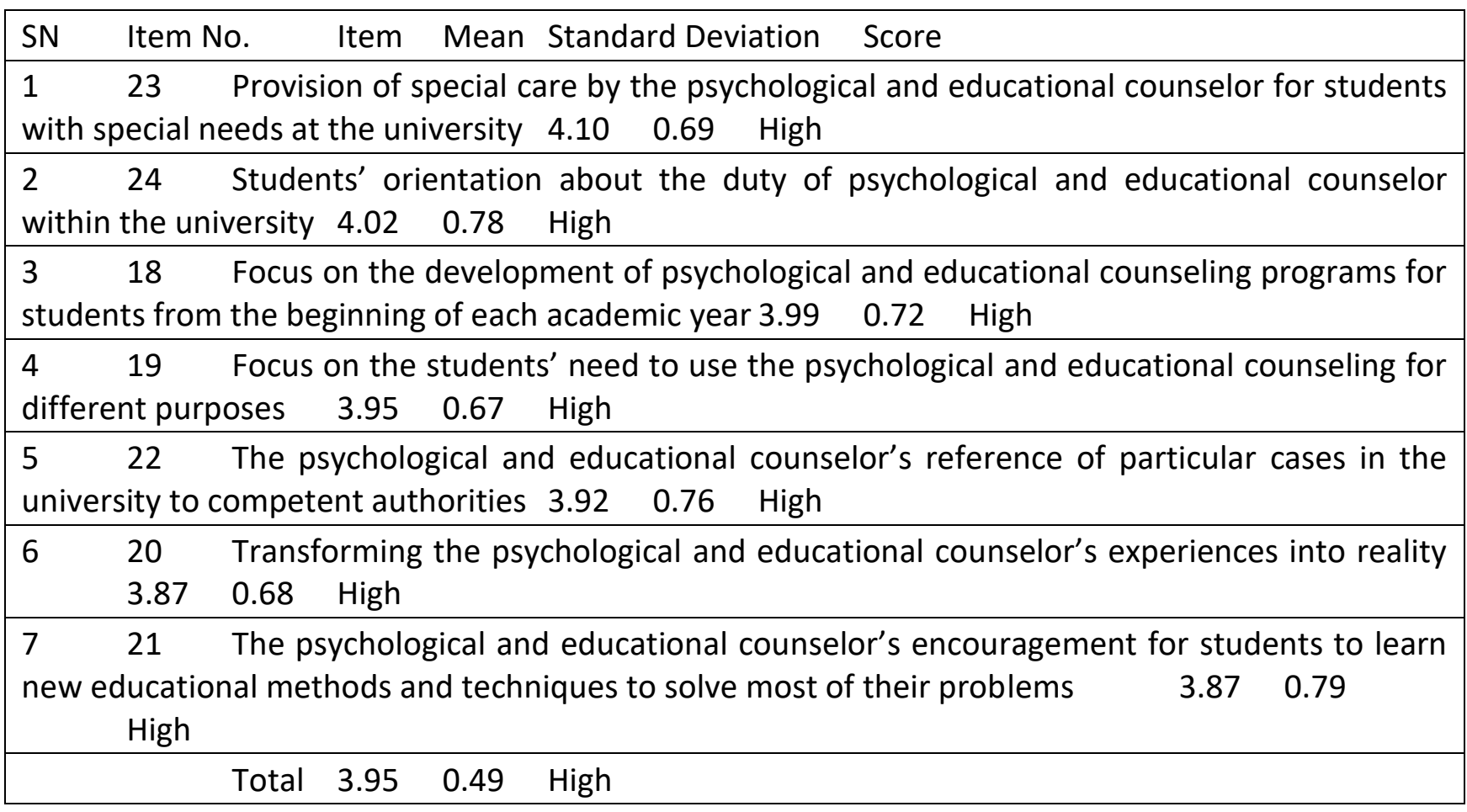

Table 4 shows that the respondents' perception about the development of the psychological and educational guidance program at Hebron University is high, with a high mean score of 3.95 and a standard deviation of 0.49 . Item 23: "Provision of special care by the psychological and educational counselor for students with special needs at the university" ranked first with a high mean score of 4.10. Item 21: "The psychological and educational counselor's encouragement for students to learn new educational methods and techniques to solve most of their problems" ranked last with a high mean score of 3.87 .

Response to the research hypothesis: There are no statistically significant differences at significance level of (0.05) in the importance of counseling, educational and psychological needs of the students in psychological and educational counseling program at Hebron University in relation to the study variables (gender, academic year, place of residence) from the students' perspective.

To address this hypothesis, Multiple Anova was used. Table 5 represents the findings. 
INTERNATIONAL JOURNAL OF ACADEMIC RESEARCH IN BUSINESS AND SOCIAL SCIENCES

Vol. 8, No. 10, Oct. 2018, E-ISSN: 2222-6990 @ 2018 HRMARS

Table 5

Findings from Multiple Anova on the differences in the respondents' perception according to the study variables (gender, place of residence, and level of study)

\begin{tabular}{|llllllll|}
\hline $\begin{array}{l}\text { Variables } \\
\text { Significance }\end{array}$ & Total squares & Degree of freedom & Mean Square P Value & Level \\
\hline Gender & 8.64 & 1 & 0.309 & 0.976 & 0.513 & \\
\hline Place of residence & 13.52 & 2 & 0.483 & 0.868 & 0.654 \\
\hline Educational level & 32.895 & 4 & 1.175 & 1.075 & 0.393 \\
\hline Error 75.44269 & 1.093 & & & & \\
\hline Total 701 & 98 & & & & & \\
\hline
\end{tabular}

* Statistical significance at the level $(0.05 \alpha \alpha)$

The information in Table 5 indicate that there are no statistically significant differences at significance level of (0.05) in the importance of counseling, educational and psychological needs of the students in psychological and educational counseling program at Hebron University in relation to the study variables (gender, academic year, place of residence) from the students' perspective.

\section{Discussion of Findings}

A number of findings were obtained as follows

1. The findings indicated that there are psychological and educational needs of the students of psychological and educational guidance at Hebron University with a mean score of 3.70. The study attributed these findings to the fact that the students need awareness and psychological guidance due to the difficult conditions experienced by Palestinian youth as a result of the various political implications. The study also showed that the students of psychological counseling are more familiar with the importance of counseling and the different needs of psychosocial services and problems facing the students in achieving psychosocial compatibility.

2. The findings indicated that there are a variety of difficulties and obstacles facing the psychological counselors, as there are a number of difficulties obstructing the achievement of the psychological and educational needs of psychological counseling students. Also, the study attributes these findings to a situation where the educational counselor cannot follow up the students' problems due to their large numbers. The findings are also attributed to the barriers between the teacher and the student imposed by the traditional education system and the lack of a safe place that provides mutual trust between the student and the counselor. In addition, there is high uncertainty in the educational counselor's role, which prevents the achievement of counseling objectives.

3. The findings showed that there are proposals to achieve psychological and educational counseling needs. The study attributes these findings to the low level of interest in psychological and educational counseling in the university due to lack of general culture on the subject of psychological and educational counseling. The students of the educational counseling agreed with some of the statements made in this study, such as developing proper plans for psychological guidance, and the effort to transform the experiences of psychological counselors into reality, as well as raising 
INTERNATIONAL JOURNAL OF ACADEMIC RESEARCH IN BUSINESS AND SOCIAL SCIENCES

Vol. 8, No. 10, Oct. 2018, E-ISSN: 2222-6990 C 2018 HRMARS

awareness for students about the role of educational counselors in developing their mental health at all levels of education.

\section{Recommendations}

The following recommends are offered based on the findings.

1. There is a need to pay maximum attention to the needs of counseling students by providing guidance models and working on their actual implementation.

2. There is a need to provide solutions to the educational and psychological problems facing students at Hebron University.

3. There is a need to pay more attention to psychological and educational counseling through holding lectures and seminars that can enlighten students on the importance of psychological and educational guidance.

4. Counseling and educational services should be provided to help students develop their attitudes, directions, and abilities through the application of tests as well as scientific and educational models to serve their objectives and desires.

5. The university should eliminate all the obstacles that prevent the implementation of psychological and educational counseling programs at the university. This can be achieved by directing and educating the students about psychological and educational counseling.

\section{Acknowledgement}

Special thanks go to the Research Management, Innovation and Commercialization Centre(RMIC), Universiti Sultan Zainal Abidin.

\section{References}

Ajiz, F. (2001). Educational counseling in primary and secondary schools in Gaza governorates. Journal of the Islamic University, 9 (2).

Al-Ghamari, S. A. (2008). Counseling needs of students at Omar Al-Mukhtar University according to some variables. Department of Psychology and Special Education, Omar Mukhtar University, Libya. Al-Jawhara, I. A. (2013). Counseling needs of female students in the faculty of education at Princess Noura Bint Abdul Rahman University and its relationship with academic level. Journal of Educational and Psychological Sciences, 14 (1).

Al-Maghamsi, S. F. (2007). Educational counseling in universities and its role in meeting the requirements of national manpower development. Journal of Taibah University: Educational Sciences, 1 (1).

Bardini, A. I. (2006). The reality of educational counseling in public and UNRWA schools in Gaza governorates, Islamic University of Gaza.

Ben Zaid, J. M. (2010). Effectiveness of counseling program in the development of rational thinking among university students and its impact on some psychological variables. (Doctoral dissertation, Ain Shams University, Egypt.

Kafafi, A. (1999). Counseling and family psychotherapy. Cairo: Dar al-fikr al-Arabi.

Nuri, A. Yahya, W. (2007). Counseling Needs (Psychosocial, social, and educational) among Mosul University Students. Journal of Education and Science, 15 (3). 
INTERNATIONAL JOURNAL OF ACADEMIC RESEARCH IN BUSINESS AND SOCIAL SCIENCES

Vol. 8, No. 10, Oct. 2018, E-ISSN: 2222-6990 @ 2018 HRMARS

Salhab, S. F. (2007). University students' awareness of the role of educational counselor and its relationship with some variables, Islamic University of Gaza.

Shaheen, M. A. (2009). Students' problems at Al Quds Open University. (Doctoral dissertation), AlQuds Open University, Hebron.

Zahran, A. H. (1982). Educational counseling in the Arab world. Journal of Educational Studies, 2 (9). Zahran, S. H. (2003). Effectiveness of psychological counseling program in correcting expatriate beliefs among university students. Journal of psychological counseling, 17. 